\title{
Thoughts on the Strategy of Green Finance Supporting Rural Revitalization
}

\author{
Bo Wang \\ School of Economics and Management \\ Weifang University \\ Weifang, China 261061
}

\begin{abstract}
China's rural green industry is huge in scale, but its financial supply is obviously insufficient. Under the background of vigorously implementing the strategy of rural revitalization, the development of green finance is just in the right time. At the time the strategy of rural revitalization has provided great opportunities for rural green development, as an important innovation and driving force for green sustainable development, green finance would mobilize social capital to support the green development in rural areas, so as to promote the implementation of rural revitalization strategy. In terms of the help of green financial for rural revitalization, we should explore the long-term mechanism of "government guidance, market operation and social participation" and clarify and balance the relationship between the three parties, governments, markets and society, and coordinate the functions of the three. With green credit as the core, green finance support joint effort shall be formed with the new kinetic energies of green bonds, green funds and green insurance, so as to jointly promote rural revitalization and green sustainable development.
\end{abstract}

Keywords-green development; green finance; rural revitalization; mechanism

\section{INTRODUCTION}

General Secretary Xi Jinping pointed out in the reports of 19th CPC National Congress: We should speed up the structural reform of ecological civilization and build a beautiful China. The need to promote green development is emphasized: it is necessary to accelerate the establishment of legal system and policy orientation of green production and consumption, establish and improve the economic system of green low-carbon cycle development; and build a marketoriented green technology innovation system and develop green finance. In the new era, for the purpose of implementing the new concept of development, green development should be taken as one of the main contents of new development concept, which has become an important part of $\mathrm{Xi}$ Jinping's socialist ideology with Chinese characteristics in the new era.

In the Party's the 19th CPC National Congress, it is clearly stated that China's economy has shifted from high speed developmental stage to high quality development stage. In order to achieve high quality economic development in the new era, we need to build a modern economic system. However, under the condition that the contradiction between resources environment and economic development is becoming increasingly prominent today, it is difficult to sustain the extensive development model at the cost of resource consumption and high environmental costs in the past. With China's economy entering the "new normal" in an all-round way, the development of green economy has become an inevitable choice to break the current bottleneck of resources environment, which is also the internal demand of promoting the transformation and upgrading of China's economic structure, accelerating the transformation of old and new kinetic energy, and realizing sustainable development. Among them, green finance is the core and weapon of green economic development, as well as an indispensable financial system arrangement to promote the development of green economy. It is the supporting force to implement the "five tasks" and ensure the "green transformation of traditional industries" and cultivate the "emerging strategic industries", and also the inherent requirement of pushing forward the supply-side structural reform from the financial level and promoting the real economy of financial services.

In 2018, the No.1 Central Document deployed the strategy of Rural Revitalization, in which it is put forward that we should adhere to "the green ecological orientation and promoting sustainable development of agriculture and rural areas" and "the harmonious coexistence of man and nature and taking the road of green development in rural areas". The implementation of rural revitalization strategy cannot be carried out without financial support. It is necessary to vigorously promote institutional innovation in the financial field and strengthen institutional supply for rural revitalization. "We should expand investment and financing channels and strengthen investment in rural revitalization; perfect the rural financial system suitable for the characteristics of agricultural and rural areas, strengthen the innovation of financial services, and enhance the ability and level of finance supporting rural revitalization". The issuance of this national strategy document has undoubtedly opened up a new space for rural green development. At the same time, it also provides a great opportunity for green finance to support rural revitalization.

\section{GREEN FINANCE SUPPORTING RURAL REVITALIZATION AT THE RIGHT TIME}

Rural rejuvenation is a long-term and complicated systematic project, in which the three rural issues are the fundamental and key links. In order to realize the comprehensive rejuvenation of the countryside and realize the 
strong agriculture, the beautiful countryside and the rich peasants, the financial strength and the basic role are indispensable. General Secretary Xi Jinping pointed out at the national financial work conference held last year that the state encourages the development of green finance, and takes it as an important grasp to promote financial "breaking away from virtual reality" and serve the development of real economy. In December 2017, the central rural work conference pointed out that, in order to implement the strategy of rural revitalization, we should adhere to the green ecological guidance and improve the rural financial system suitable for the characteristics of agricultural and rural areas. As an important part of the rural financial system, green finance plays an important role in coordinating the development of rural green industry, strengthening the management of rural ecological environment, and supporting rural green construction. Through the deep integration with the rural revitalization strategy, we constantly innovate the operation mechanism and service mode, optimize the allocation of financial resources and make up for the shortage of financial services in the construction of rural ecological civilization. It will improve the accuracy of financial support for agricultural development, rural construction and farmer richness, and provide innovation and new kinetic energy for sustainable development of rural areas.

However, at present, the supply of green finance and rural Revitalization do not match the needs of green finance. From the supply side, the local small and medium-sized financial institutions, as the main supplier of rural green finance, are not conscious enough to develop green finance and lack of endogenous motivation. To a large extent, due to the pressure of higher-level assessment and political requirements to carry out green financial business, weak market participation and lack of business sustainability, its green financial products and services are less professional and innovative, which is difficult to meet the vigorous demand of green finance in the rural revitalization process. From the demand side, under the background of fully implementing the strategy of rural revitalization, whether the improvement of rural living environment, the development of recycling green agriculture, or the construction of beautiful countryside, all needs a lot of capital investment. It is estimated by the relevant departments, in recent years, China's rural green demand for finance is about 1 trillion Yuan per year. But the government's financial contribution can only meet $20 \%$, and the supply gap of green funds is larger. In addition, there are a series of problems in rural green projects, such as small scale, scattered location, long investment cycle, uncertain income and lack of credit information. And it is difficult to fundamentally solve the contradiction between supply and demand of green funds only relying on the strength of the government. It is necessary to give full play to the leading role of the market and strengthen the institutional construction of green financial market and the capacity building of participants, cultivate and innovate green financial instruments in rural areas, widen the channels for social capital to enter the green industry in rural areas, mobilize and encourage more social capital to participate in the green development of rural areas and help the implementation of rural revitalization strategy.

\section{LONG-TERM MECHANISM OF GREEN FINANCE SUPPORTING RURAL REVITALIZATION}

Green finance has developed so far, the role positioning of government and market has been the core of contradiction and the focus. In terms of market role and government role, General Secretary Xi Jinping pointed out that "invisible hand" and "visible hand" should be used well, and efforts should be made to form a pattern of organic unity, mutual complementation and mutual promotion between market role and government role. Based on the fact that China's green finance is still in the primary stage of development and the supply and demand of green finance are unbalanced in the process of rural revitalization, nowadays we urgently need to construct a mechanism framework of "government guidance, market operation, social participation" for green finance supporting rural revitalization, and clarify and balance the relationship among government, market and society. Firstly, with the help of government as "visible hand", we should issue the guidance on the rural revitalization of financial services, improve the relevant system construction and incentive and restraint mechanism, and give full play to the leading role of $\mathrm{ADBC}$ and other policy financial institutions in green financing. It can effectively leverage and guide more financial resources allocation to the key areas of rural revitalization, to maximize the diversified financial needs of rural green development. Secondly, we should make full use market as the invisible hand to introduce the market mechanism, strengthen market system construction and market participants' capacity building, and speed up the construction of a multi-level rural green financial market system. It is also necessary to make continuous innovation of rural green financial instruments and services to meet the multi-level rural revitalization and diversified green financing needs. In particular, we should pay attention to the commercial sustainability of rural green finance, fully utilizing the regulatory function of the market to solve the contradictions between public welfare and profitability, high risk and low income in the process of green finance supporting rural revitalization, and cultivate the endogenous motive force for its sustainable development, so that it can improve the overall competitiveness of market, let market play a decisive role in the allocation of resources, and let more green financial resources promote the implementation of the strategy of rural revitalization. Finally, we should deepen the depth and breadth of social forces participating in green finance supporting rural revitalization. We should attach importance to the cultivation and propagation of green concept of the whole society, including cultivating and strengthening the green performance concept of government officials, the green financial concept of financial employees, and the green production concept of enterprises and the green consuming of ordinary people. So that it can let green ideas go deep into government decision-making, financial services, production investment and consumption, advocate the whole society to form a production, living and consumption mode that is saving environment, green and low-carbon. We should strengthen the training of green finance professionals, and focus on training compound professionals with both financial knowledge, environmental protection technology and environmental protection laws and regulations, and regularly 
hold seminars on green finance training for local Party and government leading cadres, so as to improve the innovative ability and management level of green financial services in rural areas as soon as possible. We should increase the publicity and education of green finance in rural areas and strengthen the publicity and interpretation of green development plan, green industrial policy and green financial policy in rural areas, so as to make the popularization of green finance knowledge in rural areas normalize, and create a good macro environment and development atmosphere for green finance supporting rural revitalization.

\section{Mode ANALYsis ON GREEN FINANCE HELPING RURAL REVITALIZATION}

It was clearly defined in the central rural work conference at the end of 2017, that the objectives and tasks of implementing the rural revitalization strategy, and proposed that by 2020, the rural revitalization has important progress, and the institutional framework and policy system are formed basically. By 2035, the rural revitalization has decisive progress, and the modernization of agriculture and rural areas has basically been realized. By 2050, the countryside is revitalized in an all-round way, and the beautiful countryside, rich peasants and financial strength is fully realized. To achieve these goals, we need to give full play to the advantages of finance in resources, platforms and specialties, dig deeper into the potential of financial support for the development of real economy and eliminate the blind spots in rural financial services, so as to crack the bottleneck restricting the implementation of rural revitalization and making up for the shortage of rural financial supply. Among them, green finance is an important component and major innovation of China's financial system, which is the core and weapon to promote the development of green economy in China, but also an important support force to promote the smooth implementation of China's rural revitalization strategy. Under the background of vigorously implementing the strategy of rural revitalization, green finance has been given a higher mission and richer connotation. Green finance should be based on the origin of financial service entity economy when it comes to the strategy of rural revitalization, focused on rural green development projects with commercial value and ecological value potential but facing funding bottlenecks. The main points of support are mainly in the following aspects.

\section{A. Green Credit}

Based on China's bank-oriented financial system, green credit is the foundation and core of China's green finance, as well as the main channel for indirect financing of green finance. According to the statistics, in 2017, China's green credit balance accounted for more than $95 \%$ of all kinds of green financing balance. Combing the investment direction of green credit in recent years, it can be found that most of the credit flows to key projects with market size and economic benefits, such as green energy, green transportation, energy saving and water saving. For green projects closely related to rural revitalization such as green agriculture, rural garbage disposal and sewage treatment, owing to the problems of small scale, high risk, long investment cycle, uncertain income and insufficient guarantee, if it is expected to produce good environmental and social benefits, though it still falls outside the key support areas of green credit support. Based on this, it is suggested that the relevant government departments should, according to the development of rural revitalization and the characteristics of financial demand, introduce relevant policies as soon as possible, improve the incentive and restrictive mechanism of green credit to support rural revitalization, and guide banking financial institutions to actively provide medium and long-term credit support for green projects such as rural green agriculture, rural environmental governance and rural ecological protection. At the same time, it is suggested that banking financial institutions should strengthen green credit products and guarantee mode innovation, and pilot and promote mortgage loans such as carbon emission rights, emission permits and energy use rights, so as to solve the problem of green financing guarantee in rural revitalization. In addition, it is suggested that the relevant government departments and financial institutions should have close communication and cooperation with each other, increase institutional reform and institutional innovation in the field of green credit, moderately relax market access and appropriately increase the risk tolerance of green credit. It is also necessary to continually optimize the green credit and approval processes, set up a special channel to rural revitalization green credit, and establish and improve the policy support mechanism of green credit supporting rural revitalization.

\section{B. Green Bonds}

Since 2016, China's green bond market has developed rapidly, and green bond issuance has appeared an explosive growth. In the past two years, the issuing scale of green bonds has maintained at about 200 billion Yuan, leading the global green bond market. Nevertheless, the annual issuance of green bonds accounts for only about $0.3 \%$ of the total stock of China's bond market. At present, green bonds are mainly issued by banks and other financial institutions. Other types of green non-financial bonds, such as corporate bonds, corporate bonds and asset-backed securities, account for a relatively low proportion and are difficult to form in the short term. Therefore, China's green bond market has great potential for development, and green bond products have great innovation space. In addition, it is cleared in Green Bonds Support Project Catalogue issued by the Central Bank of China that the main direction of green bond raising funds will focus on energy conservation, environmental protection, pollution prevention, clean transportation, clean energy and ecological protection. And it is highly consistent with the green projects involved in the strategy of rural revitalization in China, and belongs to the scope of key objects supported by the green bond project catalogue. Based on this, it is suggested that government departments and relevant financial institutions should give full play to the characteristics of green bond instruments, use policies to guide green bonds to provide direct financing channels for medium and long-term rural revitalization green projects. And they should have a flexible use of financial subsidies to reduce its issuance costs, ensure that the green bond issuer's cost and income matching and business sustainability and good cycle, and enhance investors' confidence. In addition, we should encourage financial 
institutions to launch special bonds for green development in rural areas as soon as possible, open up a special bond financing channel for rural revitalization's green projects, reduce the cost of capital use of related enterprises and increase the convenience of financing and the availability of funds.

\section{Green Fund}

In recent years, the 13th Five-Year Plan Outline and Guiding Opinions on Construction of a Green Financial System and other government documents have clearly put forward support for the establishment of various types of green development funds. Under the guidance of government policies, the types and quantity of green funds in China have increased dramatically, and their ability to absorb and enlarge social capital has been strengthened continuously. At the national level, the central government has set up the national green development fund through integrating special funds such as energy conservation and environmental protection. At the local level, the local government actively absorbs all kinds of investment entities such as local financial institutions, investment institutions, state-owned enterprises and private enterprises to jointly launch a regional green development fund. The diversification of green fund investors is conducive to the formation of synergy between industrial policies and financial policies, and the deep integration of industrial entities and financial instruments. Compared with other green financial instruments, green fund brings together the advantages of investors in policy, capital, resources, technology, information and talent. With it participating in the operation of green projects by means of equity investment, the exit mode of the later projects has been planned in advance at the beginning of the investment. Therefore, it has a more perfect market operation mechanism and development potential. In the future, the green fund will become an important financial tool and driving force to revitalizing the green development of rural areas. Based on this, it is suggested that relevant government departments should actively participate in the market-oriented operation of green fund and scientifically evaluate the development strategy and project decision-making of green fund, so as to standardize and guide the investment direction of green funds, mobilize more financial resources to focus on rural green development projects. At the same time, we should actively respond to the No. 1 central document in 2018 that "supporting eligible agricultural enterprises to be issued and listed, new threeboard listing and financing, merger and reorganization", and truly realize the market-oriented operation of green fund and maximize investment benefits. In addition, following the national green industry policy orientation, more local governments should be encouraged to set up green development funds in accordance with national policies and local conditions, so as to guide more private capital to enter the green finance field and better support the rural green development and rural revitalization strategy.

\section{Green Insurance}

In China, green insurance usually refers to environmental pollution liability insurance (hereinafter referred to as "environmental liability insurance"), which is based on the liability of compensation and management for the damage caused by a company's pollution accidents to the third party. In 2007, China started the pilot project of environmental liability insurance, but due to the imperfect laws and regulations, low insurance compensation rate and other reasons, the willingness and enthusiasm of enterprises to insure is low. In 2013, the Joint Insurance Regulatory Commission of the Ministry of Environmental Protection began to select some provinces and municipalities to carry out compulsory environmental liability insurance pilot. Although the amount of insurance has increased, the overall scale still does not match the size of China's trillion-dollar premium market. In recent years, with the development of the central environmental protection supervision and the implementation of new Environmental Protection Law which is the most rigorous one in history, the importance and market position of green insurance have gradually become prominent, and the market scale has been expanding. As an important part of green financial market system, green insurance has the characteristics large capital stock, long life and stable cash flow, which is an ideal financial tool to support rural revitalization projects with large financing demand and long investment cycle, such as green circular agriculture and green industrial park. Based on this, it is suggested that the government departments, on the one hand, further strengthen the supervision of environmental protection and maintain the high-pressure situation of ecological environment protection. On the other hand, financial institutions should increase the publicity and promotion of green insurance products and business, and help improve the market-oriented operation mechanism for green insurance as soon as possible, so as to achieve large-scale, market-oriented and standardized development and provide a stable financial supply for the implementation of rural revitalization strategy. In addition, it is suggested that relevant financial institutions should strengthen the system construction and capacity building of green insurance market. It is also necessary to intensify innovation in green insurance products and business models and effectively integrate them with financial instruments such as green credit, green bonds and green funds, so as to form a joint force of green finance supporting rural revitalization and jointly promote the smooth implementation of rural revitalization strategy.

\section{CONCLUSION}

Rural revitalization, a major strategy of China, is also a long historical mission. As this strategy approaches, the agriculture and rural areas in our country has seen unprecedented opportunities, and the green economy in rural areas will also enjoy its gold years. The rural revitalization strategy being fully implemented,now is the best moment for green finance. To make it better serve the strategy, we should set up a long-term mechanism w here the green finance is led by the government, operated by the market and participated by the public. We should also clarify and balance the relationship among government, market and society, and better coordinate their functions. At the same time, we should arrange the financial tools including green credit, green bonds, green fund and green insurance as a whole to form a joint force of green finance supporting rural revitalizing. This will guide more high-quality element resources to be distributed to 
the green industries, so as to make the green finance an essential leading force and supporting force.

\section{REFERENCES}

[1] Ma Jun. Discussion on Building China's Green Finance System [J]. Finance Forum, 2015, (5): 18-27.

[2] Yan Chengliang, Li Tao, Lan Wei. Financial Development, Innovation and Carbon Dioxide Emissions [J]. Journal of Financial Research 2016, (1) : 14-30.

[3] An Tongxin, Hou Xiaomin, Yang Yang. Research on Theoretical Connotation and Realization Path of China's Green Finance Development [J]. Dongyue Tribune, 2017, (6): 92-100.

[4] Zhang Chenghui, Xie Mengzhe. China Green Finance: Experience, Path and International Reference [M]. China Development Press, 2015.

[5] Chiara Criscuolo, Carlo Menon. Environmental Policies and Risk Finance in The Green Sector: Cross-Country Evidence. Energy Policy, 2015.

[6] Wang Yao, Pan Dongyang, Zhang Xiao. Research on Contribution of Green Finance to China's Economic Development [J]. Comparative Economic and Social Systems 2016, (6): 33-42.

[7] Li Ruoyu. China's Green Finance Development Status and Policy Recommendations [J]. Macroeconomic Management, 2016, (1): 58-60.

[8] Liao Xiaodong, Shi Jun. Green Governance: a New Analytical Framework [J]. Management World, 2017, (6):172-173.

[9] Yao Wang, Qiang Zhi. The Role of Green Finance in Environmental Protection: Two Aspects of Market Mechanism and Policies. Energy Procedia, 2016

[10] Li Xiaoxi. Analysis of Relation between Profitability of Green Finance and Public Welfare [J]. Finance Forum, 2017, (5): 3-11.

[11] Jiang Xianling, Zhang Qingbo. Review of Green Finance Theory and Practice in Developed Countries [J].Population, Resources and Environment in China, 2017, (5):323-326.

[12] An Guojun, Liu Kun. Influence of Green Finance on Rural Revitalization [J]. China Finance, 2018, (10):63-65.

[13] Li Hao. Consideration of Green Finance Supporting Rural Revitalization Strategy [J]. Financial View, 2018, (4): 16-17.

[14] Wang Bo, Zheng Liansheng, Wang Zhaobin. Research on Long-term Mechanism of China's Green Finance Development under New Normal [J]. Technoeconomics \& Management Research, 2018, (8): 83-88.

[15] CPC central committee Opinions of State Council on Implementation of Rural Revitalization Strategy[R]. Communiqu of State Council of the PRC, 2018-2-20. 